\title{
Strategic vs Definitory Rules: Their Role in Abductive Argumentation and their Relationship with Deductive Proof
}

\author{
Bettina Pedemonte ${ }^{1^{*}}$ \\ ${ }^{1}$ San Jose State University, CA, USA
}

Received 25 April 2018 • Revised 23 May 2018 • Accepted 28 May 2018

\begin{abstract}
This paper analyzes the role of abduction in proving process when students solve a geometrical problem. Solving a problem is like playing a game in which rules have to be defined. Two kinds of rules are considered: definitory rules that define the basic moves in the game and strategic rules that explain how to play the game. These two rules can be associated to two types of abductions that can be used to solve geometrical problems. The purpose of this paper is to compare these two abductions and to analyze their relationship with the deductive proof. In particular, the study reveals that abduction based on definitory rule can be an obstacle to the construction of the deductive proof, while abduction based on strategic rule seems to not be a challenge for students. In fact, this abduction is usually transformed into a deduction along the argumentation.
\end{abstract}

Keywords: abduction, argumentation, proof, strategic rule, definitory rule, cognitive unity

\section{INTRODUCTION}

The term abduction was introduced into modern logic by Peirce (1867). It was introduced to denote a non-deductive inference different from the inductive type. As shown in Fann's work (1970) there is not consistent idea and coherent picture about abduction in Peirce's work. Peirce used abduction in different ways, and he referred to it with different terms, including Hypothesis Presumption and Retroduction.

In its general form, abductive reasoning is a form of logical inference which starts with a set of observations then seeks to find the simplest and most likely explanation. However, abduction is currently used in many different applications - artificial intelligence, medicine, philosophy, science of language, logic - and it has different meanings according to the research fields in which it is used. Furthermore, inside a precise domain we can find different ideas and shadows associated to it. In mathematics education, the term "abduction" is used to refer to a number of different processes and in relation to different activities. Abduction has been considered in relation to mathematical activity in general (see, e.g., Cifarelli \& Sáenz-Ludlow, 1996; Krummheuer, 2007; Mason, 1996; Rivera, 2007), and it has been studied to explore ways in which it may be implemented in the mathematical classroom (Rivera 2017). Many researches have considered abduction in relation to mathematical proof (see, e.g., Antonini \& Mariotti, 2003, Arzarello, Micheletti, Olivero, \& Robutti, 1998 a,b; Knipping, 2003, Pedemonte \& Reid 2011; Pedemonte, 2007, 2008) to compare it with other forms of reasoning like deduction or induction.

In these studies, abduction is often described as "an inference which allows the construction of a claim starting from an observed fact" (Pedemonte, 2007, p. 29) with reference made to the work of C. S. Peirce (1960). However, it was observed (Pedemonte \& Reid, 2011) that this definition also includes at least three subtypes of abductions: overcoded, undercoded and creatives abductions (Eco, 1983, Bonfantini \& Proni, 1983; Magnani 2001). Each of these abductions has specific characteristics inside the argumentation and it can be associated to specific cognitive difficulties students may encounter using it in proving process.

Empirical studies (Rivera, 2017) illustrated the relationship between abduction and the emergence of necessary mathematical knowledge pointing out four characteristics of abduction: guessing process, developing and

(C) 2018 by the authors; licensee Modestum Ltd., UK. This article is an open access article distributed under the terms and conditions of the Creative Commons Attribution License (http://creativecommons.org/licenses/by/4.0/). $\square$ bettina.pedemonte@gmail.com (*Correspondence) 


\section{Contribution of this paper to the literature}

- This paper focuses on the relationship between abductive argumentation and deductive proof when students solve a geometrical problem.

- Two kinds of abductions are considered: abduction based on definitory rules and abduction based on strategic rules.

- Abduction based on definitory rules can be an obstacle to the construction of the deductive proof. Opposite, abduction based on strategic rules can be transformed into a deduction along the argumentation process.

entertaining inferences toward a law that will be tested via induction, inference that yield the best explanation, and explanation or justification that do not prove. Examples from the classroom provided in this study show that different arguments can be considered as abductions according to the specific mathematics education research. These different characteristics also show that abduction can be related to the whole process to solve the problem or it can be a part of this process, as a single step inside an argumentation.

Research in this field is clearly not fulfilled. The purpose of this paper is to move a step forward in this research focusing on two particular kinds of abductions that can emerge in proving process: abduction derived by strategic rule and abduction derived by definitory rule.

Hintikka and Bachman (1991) define strategic rule versus definitory rule. Definitory rules define the basic moves and tell you what is and what is not admissible in a game. Strategic rules tell you how to play a game. Strategic rules are usually more difficult to formulate. They often have to be learned and developed by practicing the game (Hintikka \& Bachman 1991, p. 32).

Solving a geometrical problem involving the construction of proof is similar to playing a game. Definitory rules are theorems and properties acceptable in Geometry and strategic rules are given by selecting the "good" theorems and/or properties that can lead to the solution of the problem.

Definitory and strategic rules can be found in the argumentation developed by students to solve a problem. In general, they appear as rules of inference in steps of argumentation. This paper analyzes these rules when they are part of abductive arguments. Definitory and strategic rules can be part of two different abductions. Abduction derived by strategic rule is usually present at the beginning of argumentation when students select a strategy to solve a problem. They perhaps still do not know if the chosen strategy allows them to find the solution of the problem. It represents their hypothesis to solve it. They look for data and inferences to apply the strategy. This is why it is called abduction based on strategic rule. This abduction is present in the argumentation at meta-level because once it is formulated, or at least chosen, it leads the process of argumentation. On the contrary, abduction derived by definitory rule is associated to a single argument (a step of argumentation) and it is used when theorems and/or data are searched to justify a particular claim inside the argumentation.

Research about cognitive continuity highlighted that abduction can represent an obstacle for the construction of deductive proof in Geometry (Pedemonte, 2007). However, these studies generally considered single abductive steps in the argumentation, mainly based on definitory rules.

The aim of this paper is to compare definitory rules and strategic rules in abduction to analyze if abduction based on strategic rule can also represent a cognitive difficulty for the construction of deductive proof in Geometry.

\section{ABDUCTION AND COGNITIVE CONTINUITY}

Educational research highlighted that when students solve an open problem using an argumentation activity to construct a conjecture, continuity between argumentation and proof, called cognitive unity (Boero et al. 1996) can be observed.

During the production of the conjecture, the student progressively works out his/her statement through an intensive argumentative activity functionally intermingled with the justification of the plausibility of his/her choices. During the subsequent statement-proving stage, the student links up with this process in a coherent way, organizing some of previously produced arguments according to a logical chain (Boero et al., 1996, p. 119).

Experimental research about cognitive unity (Boero \& al., 1996; Garuti, Boero, Lemut, Mariotti, 1996; Garuti, Boero, \& Lemut, 1998; Pedemonte, 2005) shows that proof is more "accessible" to students if an argumentation activity is developed for the construction of a conjecture. The teaching of proof, which is mainly based on "reproductive" learning (proofs are merely presented to students, they do not have to construct them) appears to be unsuccessful. On the contrary, open problems (Arsac, Germain, \& Mante, 1991) which require a conjecture, 
appear to be extremely effective for introducing the learning of proof because the argumentation activity seems to favor the construction of proof (Boero et al., 1996).

Following these research studies, it was shown that the analysis of cognitive unity does not cover all aspects of the relationship between argumentation and proof. In particular, cognitive unity does not take into account the analysis of a structural continuity between these two processes. There is structural continuity between argumentation and proof when inferences in argumentation and proof are connected through the same structure (abduction, induction, or deduction). Argumentation and proof do not usually have the same structure: proof is deductive while argumentation is characterized by other forms of reasoning like abduction or induction. To construct a proof, the structure of argumentation needs to be transformed into a deduction. Thus, there is usually structural distance between argumentation and proof, that is one of the possible difficulties met by students in the construction of geometrical proof (Pedemonte, 2007). As a matter of fact, sometimes students are unable to construct a proof in Geometry because they are not able to transform the abductive structure of argumentation into deductive structure (for example, it is not unusual to find abductive steps in students' proof if they have previously produced abductive argumentation).

However, research results are complex and very often cannot be generalized. For example, unlike the geometrical case, the structural distance between argumentation and proof is not one of the possible difficulties met by students in solving algebraic problems. In general, students are able to construct a deductive algebraic proof even if the previous argumentation was abductive. Opposite to the geometrical case, since algebraic proof is characterized by a strong deductive structure, abductive steps in the argumentation activity can be useful in linking the meaning of the letters used in the algebraic proof with numbers used in the argumentation (Pedemonte, 2008).

A recent study in Trigonometry (Fiallo \& Gutierrez, 2017), identified categories of cognitive continuity showing that some types of continuity seem to induce students to produce deductive proofs, whereas other types seem to induce them to produce empirical proofs. These empirical proofs are often characterized by abductive reasoning. Sometimes they can be an obstacle for the deductive proof and sometimes they support the development of a generic example (Balacheff, 1988) and the construction of proof.

It is evident that the complexity of the cognitive analysis between abductive argumentation and deductive proof is a challenge for educational research. Research results are specific to the mathematical domain of reference and they often foster further questions instead of providing answers.

Furthermore, it was observed that abduction is not associated to a unique reasoning but we can have more types of abduction. Eco (1983) distinguishes among overcoded, undercoded and creative abductions. Overcoded abduction occurs when the arguer is aware of only one rule from which that case would follow. If there are multiple general rules to be selected from, Eco calls it undercoded abduction. If there is no general rule known to the arguer that could imply the given case, the abduction is called creative abduction because the arguer must invent a new rule (Eco, 1983). Some types of abduction may present obstacles both in argumentation when the abduction occurs and later when the proof is constructed (Pedemonte \& Reid, 2011). It was observed that there are kinds of abduction, overcoded abduction for example, that make deductive proof more accessible. Others, on the contrary, are more difficult to transform into deduction. For example, the creative abduction, is probably the most difficult kind of abduction to use as a basis for a deductive proof because a lot of additional checking is necessary to ensure that the created rule is an effective and correct theorem (Pedemonte \& Reid, 2011 p 286).

These types of abduction were analyzed as part of a single step inside the argumentation. However, abduction can also be considered at a meta-level when students select the strategy to solve a problem.

In this paper, this abduction is considered to be compared with the deductive proof. My hypothesis is that when students produce an argumentation to justify a conjecture, two kinds of rules can be applied in the abduction: strategic rules and definitory rules (Hintikka \& Bachman 1991). Strategic rules can be related to the abduction at meta-level while definitory rules are associated to abductive steps inside the argumentation. Research about cognitive continuity usually considered this the last type of abduction.

In the next section, definitory and strategic rules are introduced to show how they can be related to two different types of abduction. These abductions may affect argumentation and proof differently making important to analyze cognitive continuity in both cases.

\section{STRATEGIC RULE VS DEFINITORY RULE IN ABDUCTION}

In research about cognitive continuity abduction is usually considered from a structural point of view (Pedemonte, 2007, 2008). However, some studies (Pedemonte \& Balacheff, 2016) highlighted the importance of the semantic component of abduction to describe the rationale of the argumentation. The semantic component is characterized by the choices and decisions that the arguer accomplishes during abduction. Choices are made by the arguer when he selects rules and data to explain the observed fact. Pedemonte and Balacheff (2016) attempted to 
distinguish the structural and semantic components using the notion of topos (Eggs, 1994). A topos ${ }^{1}$ is a principle of argumentation (Eggs, 1994, p. 30) that can be specific to the argument, specific topos, or common to all arguments, common topos. Common topoi are independent of domains and situations. Typical examples are inference rules like deduction, abduction, induction. Specific topoi belong to a discipline or are specific to a situation: through a specific topos a conclusion can be inferred from some given data.

A common topos like abduction contains, for example, the pattern (the structure and its components) that characterizes it. However, rules, properties, and data selected by the arguer to complete abduction, depend on the situation, on the problem, and on the mathematical domain in which the problem can be solved.

Furthermore, choosing and selecting a strategy that can be used to solve the problem can be a form of abduction. But this form of abduction has to be distinguished from the abduction obtained selecting and choosing a geometrical rule to justify an observed fact.

Two sorts of rules can be distinguished in reasoning (Hintikka, 1999): the definitory rules and the strategic rules. The definitory rules tell what valid rules are in a particular system of logic, which moves are permitted and which ones are not. For example, in Geometry, theorems and how to apply them can be considered definitory rules. Strategic rules specify which strategies are better or worse than others. Strategies are related to goal-directed activity, where the ability to anticipate things, and to assess or choose between different possibilities, are important. One central point in strategic rules is that they cannot normally be judged only in relationship to particular moves, but the whole strategic situation must be taken into account (Hintikka, 1998, p. 513). This means that in strategies more than one step or move can and must be taken into account at the same time (Paavola, 2004). Students use strategic rules each time that they solve a problem. The strategy can be planned from the beginning or it can be constructed along the process. Strategic rules are important. "If you only know how chessmen are moved on the board you cannot much as say that you know how to play chess, unless you have some idea of the better and worse moves and sequences of moves." (Hintikka, 1998, p. 128). Understanding the strategies of a game is part of the mastery of that game. In a similar way, solving a geometrical problem requires to know not only the geometrical properties and the theorems necessary to solve it, but most importantly, it is to know a gained strategy to find a solution to the problem. In particular, proving process in Geometry involves the use of definitory rules in applying theorems and properties and strategic rules in selecting which theorems or properties can be useful to solve the problem.

These two rules characterize different forms of reasoning and logic (Hintikka, 1998). They can be part of abduction, deduction or other kinds of reasoning. In this manuscript, the relationship between these rules and abductive argumentation is analyzed. Hintikka does not treat abduction as a separate mode of inference. However, as pointed out by Paavola (2004), Hintikka has emphasized strategic aspects in relationship to abductive inference: "the validity of an abductive inference is to be judged by strategic principles rather than by definitory (move-bymove) rules" (Hintikka, 1998, 513).

This means that abductive argumentation produced by students to justify a conjecture has to be analyzed considering abduction derived by definitory rules, and more importantly, abduction derived by strategic rules. The first kind of abduction can be found in the single step of argumentation while abduction derived by strategic rules is present along the entire argumentation and probably decided at the beginning. Thus, abduction seems to be present at two levels: in each step of the argumentation when it is based on definitory rules and at meta-level when it is based on strategic rules.

Abduction derived by strategic rules is closed to what Peirce called Methodeutic. "Methodeutic studies the methods that ought to be pursued in the investigation, in the exposition, and in the application of truth" (Peirce, 1998, p. 272). In a similar way, Magnani introduces the concept of manipulative abduction in which the arguer, faced with a difficult situation, "elects or creates an action that structures the environment in such a way that it gives new information which would be otherwise unavailable and which is used specifically to infer explanatory hypotheses." (Park, 2017, p. 202). Manipulative abduction is based on strategic rules.

The aim of this paper is to consider abduction based on strategic rules and to analyze if it can represent a difficulty for students in the construction of proof. The structural distance between abductive argumentation based on definitory rules and deductive proof is a challenge for students who are solving problems in Geometry. We still do not know if the distance between abduction based on strategic rules and deductive proof can represent an obstacle for the construction of the proof.

Toulmin's model, presented in the next section, is used to analyze and to compare abductive argumentation and deductive proof. Definitory and strategic rules can be easily inserted in the model as part of the warrant.

${ }^{1}$ Aristotle was the first to define the topos (Rhetoric I, 2 - 1358a 11); the plural of "topos" is "topoi". 


\section{TOULMIN'S MODEL}

Toulmin's model was embraced by a large number of researchers in mathematics education (Inglis et al., 2007; Knipping, 2008; Krummehuer, 1995; Lavy, 2006; Nardi et al., 2012; Pedemonte, 2005, 2007, 2008; Weber \& Alcock 2005; Wood 1999; Yackel 2001; Yackel \& Rasmussen 2002).

An argument provides a standpoint (an assertion, an opinion) which is called a claim in Toulmin's terminology. Data are produced supporting the claim. A warrant provides the justification for using the data in support of the data-claim relationships; it can be expressed as a principle or a rule and it acts as a bridge between the data and the claim. This is the ternary base structure of an argument, but auxiliary elements may be necessary to describe it. Toulmin describes three of them: the qualifier, the rebuttal and the backing. The warrant imparts different degrees of force to the conclusion it justifies, which may be indicated by a qualifier such as 'necessarily', 'probably' or 'presumably' attached to the transition from the data to the claim. In the latter case, we may need to mention conditions of rebuttal "indicating circumstances in which the authority of the warrant would have to be set aside" (Toulmin, 1958, p. 101). So, a warrant can be defended by appeal to a backing that can be expressed in the form of categorical statements of fact (Toulmin, 1958, p. 105). A backing can be provided by a system of taxonomic classification, by a statute, by statistical results, or by a mathematical theory. The type of the backing could change greatly as one moves from one field of argument to another (Toulmin, 1958 p. 104). Then, Toulmin's model of argument contains six related elements organized as showed in Figure 1.

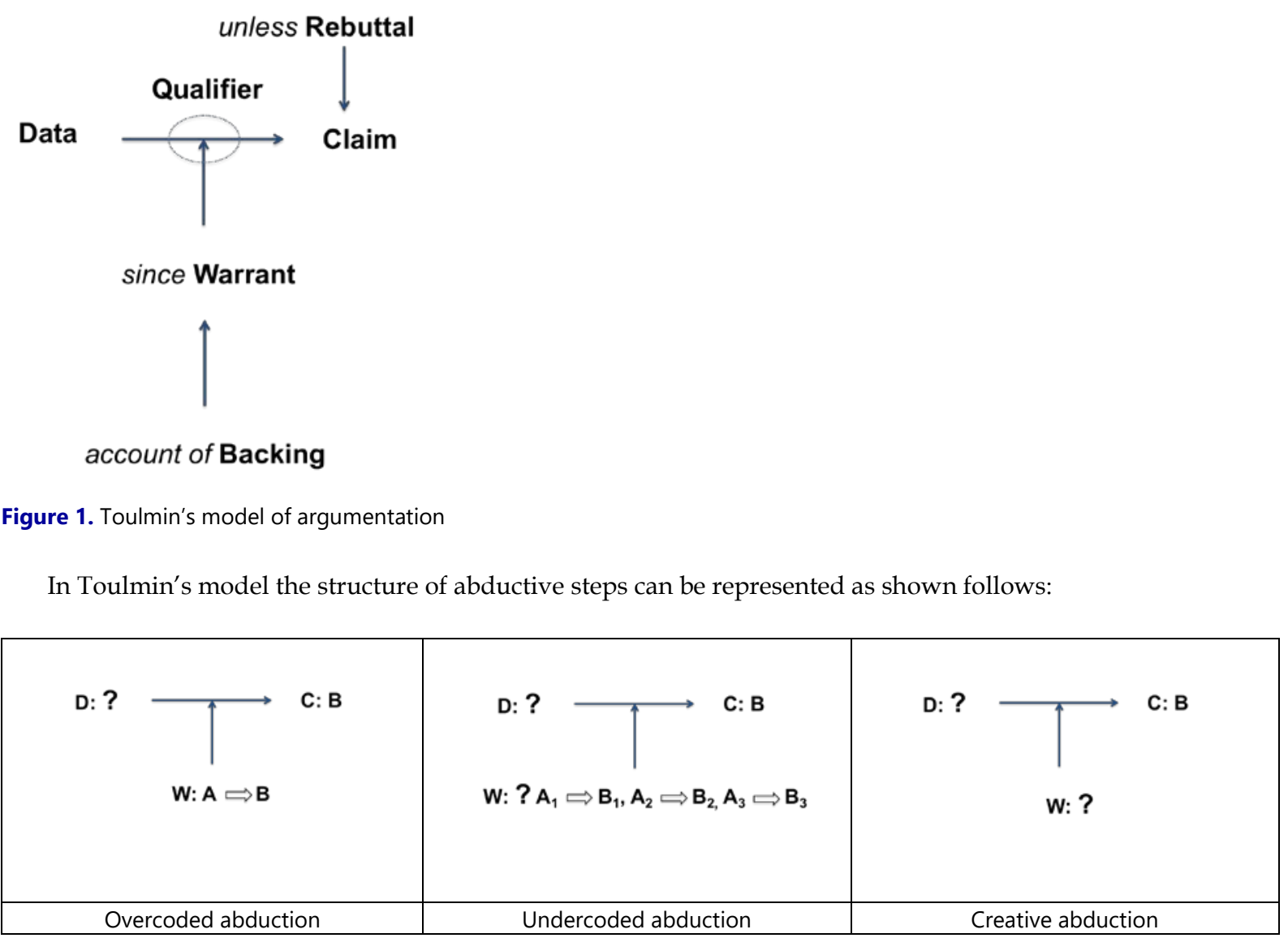

Figure 2. Representation of Abduction in Toulmin's model

The question mark in the data (D) and/or in the warrant (W) means that data and/or the warrant have to be sought to justify the claim C (that is B). There are at least three representations for abduction (Pedemonte \& Reid 2011). In overcoded abduction, a unique general rule is present as the warrant of the argument and the arguer needs to look for data to apply the rule and justify the claim. In undercoded abduction, not only data, but also a rule has to be sought to justify the claim. In creative abduction, unlike the undercoded abduction, a rule has to be created and not selected from among a set of existing rules.

In the next section, we show how Toulmin's model can be used to analyze and to compare abduction based both on strategic and definitory rules and the deductive proof. 


\section{METHODOLOGY}

The experiment presented in this paper was designed to analyze and to compare abduction based on strategic rules with abduction based on definitory rules. The purpose of the experiment is to provide insights about the cognitive relationship between abductive argumentation and deductive proof in Geometry.

It was already observed that abductive argumentation can be an obstacle to the construction of the geometrical proof because students are sometimes unable to transform abductive steps of argumentation into a deductive proof (Pedemonte, 2007). However, the abduction analyzed in this study was mainly based on definitory rules. This experiment analyzes whether this result can be extended to abduction based on strategic rules. In particular, we want to see if argumentation based on strategic rules can be an obstacle to the construction of the deductive proof.

Two problems (in the table below) were considered for this experiment.

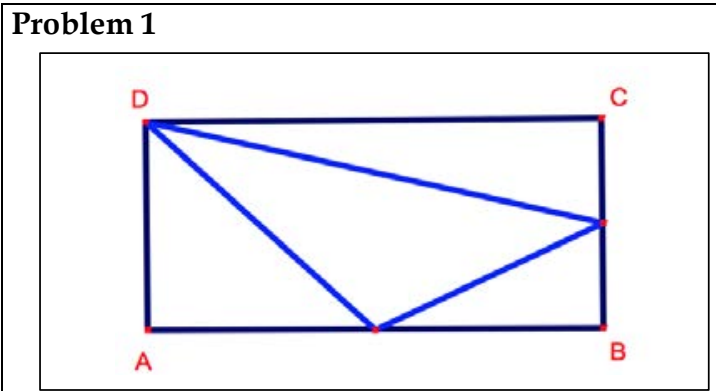

The area of rectangle $A B C D$ is 72 . If point $\mathrm{D}$ and midpoints of $\mathrm{AB}$ and $\mathrm{BC}$ are joined to form a triangle, what is the area of that triangle? (Tatiana Shubin - SJSU)

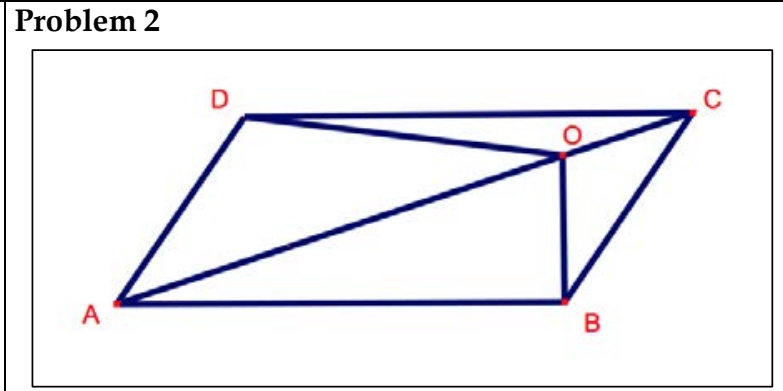

$\mathrm{O}$ is any point of a diagonal $\mathrm{AC}$ of a parallelogram $A B C D$. Compare the area of the triangles $A B O$ and ADO.

The first problem (taken by a project on Navajo students from Tatiana Shubin) was chosen because a well specific "strategic rule" is required to solve it. As a matter of fact, the area of the internal triangle is difficult to be determined using the formula of area. It is simpler to calculate the areas of the three external triangles because they are fractions of the rectangle area $(1 / 4,1 / 4$ and $1 / 8$ of 72$)$. The area of the central triangle can be obtained subtracting the areas of the three external triangles from the rectangle area. The difficult part to solve the problem is to realize that we do not need to directly calculate the area of the internal triangle. The area of the internal triangle can be obtained calculating the areas of the other triangles. Once that this strategy is selected, a straightforward solution can be obtained. The hypothesis is that the problem can be solved using abduction based on strategic rules without to use abduction based on definitory rules. Definitory rules can be part of deductions (for example to calculate the area of each external triangle) but probably they are not part of abductions.

Instead, the solution to the second problem, may require the use of both abductions (based on definitory rule and based on strategic rule). To prove that the areas of the two triangles are equal, the student can use the strategic rule derived by the area formula: two triangles have an equal area if their bases and heights are equal. However, abductions as definitory rules may be used when students observe that if $\mathrm{AO}$ is considered the common base, the two heights (on this common base) need to be equal. To prove that the two heights are equal it is possible to consider the triangles $\mathrm{ACD}$ and $\mathrm{ABC}$ and observe that the heights are equal because the triangles are equal. Another way to prove the equality between the heights, is to construct the diagonal DB and consider the two little triangles whose sides are the heights and the diagonal. The congruence theorems can be used to prove the equality between the two little triangles, as shown in Figure 3, and as consequence, the equality between the heights. In both cases, abduction as definitory rule is used because data has to be found to prove the statement (the heights are equal).

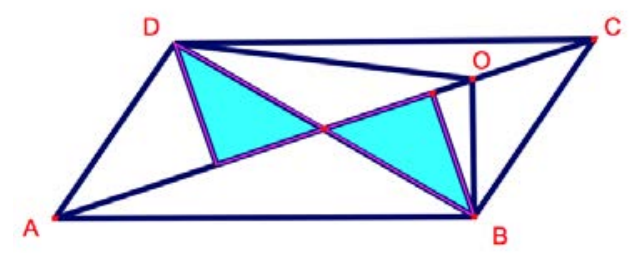

Figure 3. Possible solution of Problem 2 considering the small triangles constructed on the heights of $A O D$ and $A O B$ 
The main interest of this study was to analyze if in both cases, the structural distance between argumentation and proof represents a challenge for students in constructing a deductive proof. The hypothesis is that the construction of a deductive proof for Problem 2 should be difficult for students as shown in previous research (Pedemonte, 2007). For Problem 1, abduction might be present only as strategic rule, at a meta-level. We do not know if it can be an obstacle to the construction of the proof. The analysis should provide an answer to this question.

\section{Setting of the Experiment}

The analysis was performed with 6 Italian students and 5 Californian students. These students were 14 years old and attended different schools but each of them was in $9^{\text {th }}$ grade. All the analyzed Californian students were at the Geometry Math Course.

At this scholastic level, in Italy and in California, deductive proof is taught. All students knew the area formula for triangles as far as the triangle congruence theorems. Furthermore, every student was familiar with geometrical problems involving quadrilateral and triangles.

Each student was required to solve Problem 1 and Problem 2 individually. An interviewer was present to observe and recorder the resolution process. The interviewer could interact with the student to better explain the text of the problem and to ask for a deductive proof.

In general, the experiment doesn't last more than 30 minutes.

The students were recorded and their argumentations were transcribed (and translated from Italian into English when necessary).

\section{Analysis of the Experiment}

All students were able to construct a proof for the first problem once the good strategy was determined. Sometimes the interviewer provided a few small suggestions to help students to visualize the external triangles. For example, in two cases, when the student was stuck he asked questions like: "What is the area of this external triangle?", or: "Are you sure you can find the measure of the base and the height to calculate the area for the internal triangle?". However, he never suggested to them the strategy to use.

It was extremely interesting to observe that once the student discovered that the best strategy to solve the problem was to consider the external areas, the construction of the proof was almost straightforward. When the areas of one of the exterior triangles was determined by the student, the strategy was selected and the student found a way to determine the areas of the other two external triangles to subtract these areas from the area of the rectangle (See Case 1 below).

For Problem 2, students sometimes struggled a lot to construct a deductive proof. Even if the conjecture was determined, and a correct strategy was chosen, most students were not able to construct a deductive proof at the first attempt: abductive steps used in the argumentation were reformulated in the proof (Case 2 below).

The two cases analyzed below were selected among others because they are meaningful examples of typical resolution processes.

The assertions produced by students were identified in the transcriptions of audio recordings and the argumentation reconstructed.

Toulmin's model was used to analyze the argumentations of the students. The transcript is in the left column of the table and comments and analyses are reported on the right column.

Case 1

The analyzed argumentation and proof is provided by Ayla (A), an Italian student. The interviewer (I) is interacting with her.

In the argumentation, abduction based on strategic rules is present at meta-level. The argumentation also contains deductive steps, based on definitory rules.

At the beginning Ayla tries to solve the problem calculating the base and the height of the internal triangle. 
1. A: Do I need to find the area of the internal triangle?

2. I: Yes

3. A: Oh, ok ... umm... to find the area I need to find the base and the height... but I do not know the length of the side of the rectangle, I only know the area.

The student considers some possible values the sides of the rectangle $A B C D$ can have. For example, she considers a side of the rectangle equal 12 and the other one equal to 24 and she also considers the case in which one side is 30 and the other is 6 .

The interviewer suggests considering a generic case. After a few minutes, Ayla finally pays attention to the exterior triangles.

4. A: We know that these two points are in the middle of each side. I think we need to use this information....
The first argument is abductive. This abduction is based on a strategic rule: if base and height of the triangle are determined the area can be obtained.

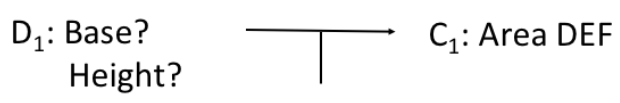

\section{W: Area formula}

Ayla tries to use the area formula to calculate the area of the triangle DEF (Figure 4), but she soon realizes that she doesn't know any side of the triangle.

She abandons this strategy after considering some specific cases for the sides of the rectangle. She looks for an alternative strategy. She considers data provided by the text of the problem: $E$ is the middle point of $A B$ and $F$ is the middle point of $B C$. She realizes (int. 4) that this information is probably useful to find the solution.

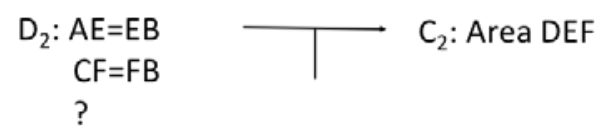

W: ?

This step is an abduction based on strategic rule. Ayla is still looking for a rule to solve the problem.

In argument 1 , Ayla considers using the formula to calculate the area of the internal triangle but she realizes that she cannot find the lengths of the base and the height for this triangle.

She looks for an alternative strategy as shown in argument 2. Ayla considers data provided by the text of the problem. She believes that the information has to be used to solve the problem. At this point, argument 2 could be an undercoded abduction or a creative abduction. Ayla looks for a theorem that can be used to justify the claim supposing that the given information $(\mathrm{AE}=\mathrm{EB}$ and $\mathrm{CF}=\mathrm{FB})$ can be used in data. However, we do not know if she is already thinking to some theorems that could help her to determine the area of DEF.

After that, Ayla realizes that because AE is equal to EB, the rectangle can be divided in two equal parts. She can find the area of the triangle AED.

5. A: But, but this triangle is... it is $1 / 4$ of the total triangle

6. I: why is it $1 / 4$ ?

She draws the axe in the triangle

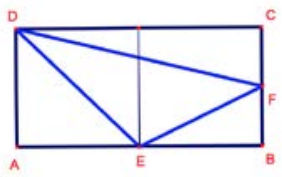

Figure 4. Ayla's drawing for Problem 1

7. A: If you divide the rectangle in 2 parts, these parts are equal and this triangle is just $1 / 4$ of the total rectangle so it is ... wait 72 divided by 4 is... (She writes the operations) it is 18

8. I: I see
The next two arguments are deductive. However, argument 2 is still present as backing of the arguments 3 and 4.

The following two arguments are based on definitory rules, but they are not abductions. Ayla uses geometric properties and computation rules to state the claims. These arguments are both deductive.

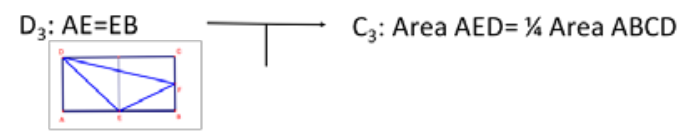

The segment in $\mathrm{E}$ divides the rectangle in 2 equals parts The rectangle can be divided in 4 equals triangles

Argument 2 


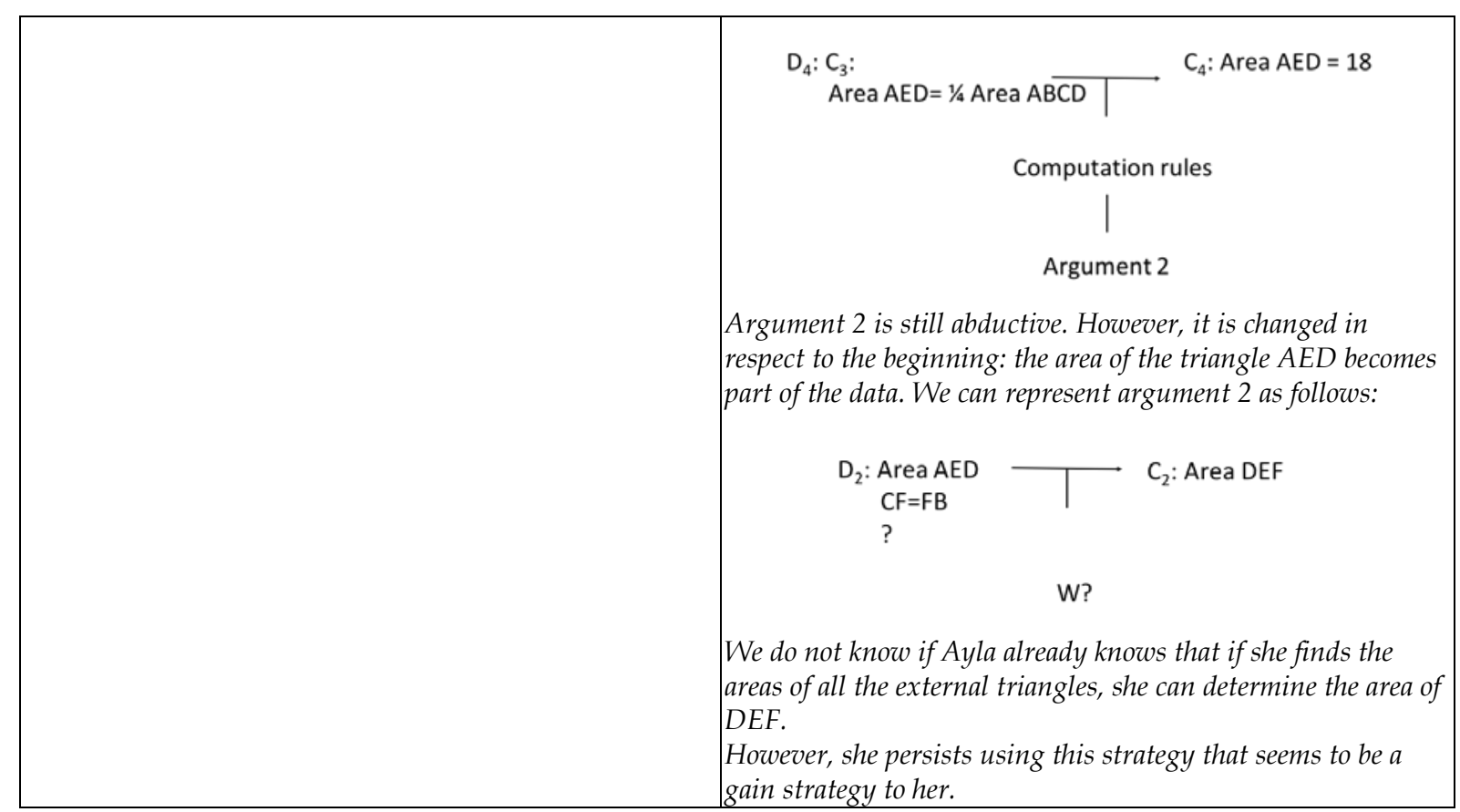

The strategy is almost determined. If Ayla is able to find the areas of the other two external triangles, she can determine the area of the triangle DEF. Ayla uses the second data provided by the text of the problem: $C F=F B$

The arguments based on definitory rules are still deductive. However, the abduction based on strategic rule is present at meta-level (as backing of the other arguments) along the argumentative process.

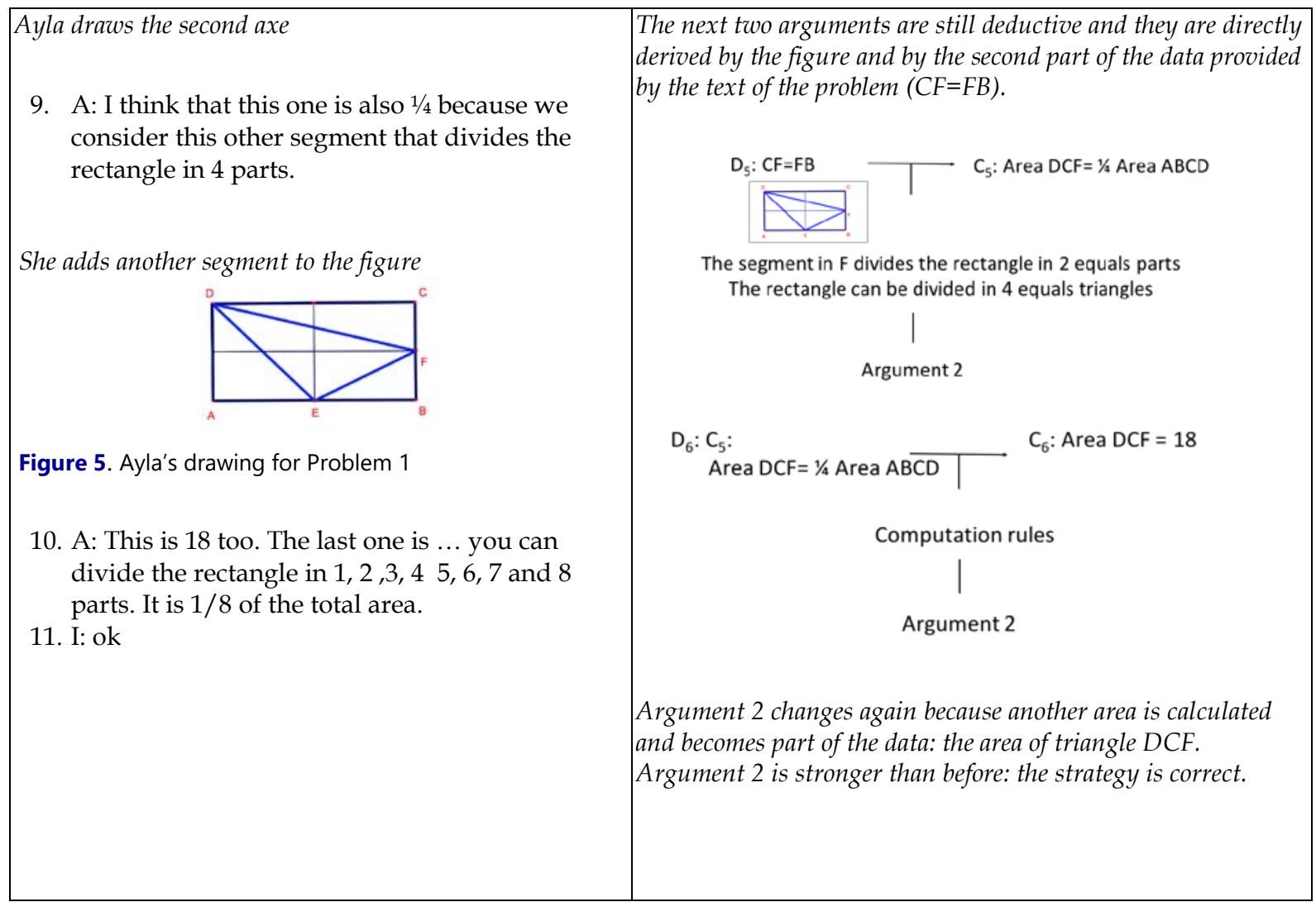




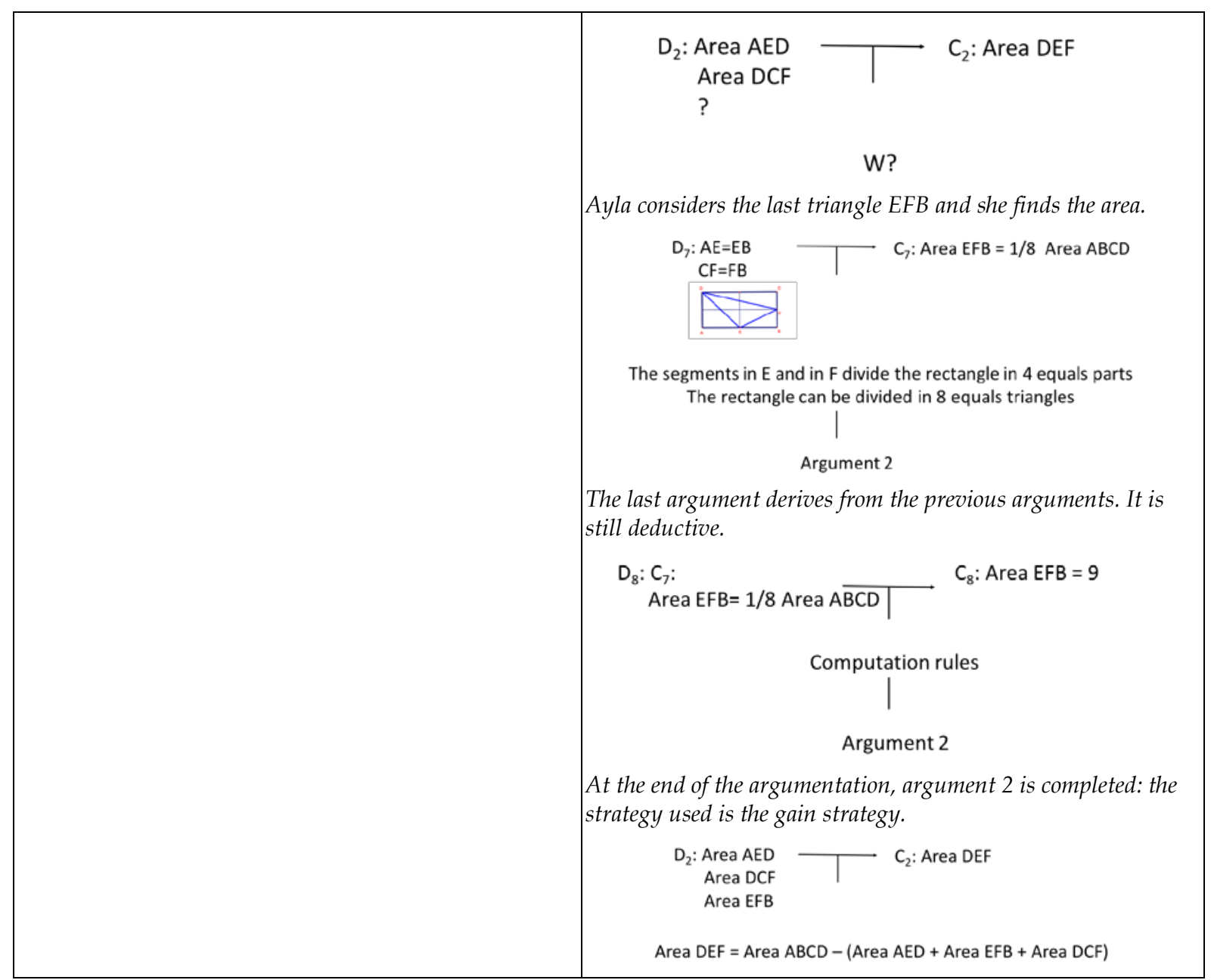

Argument 2 is not always the same in the argumentation. Little by little the strategy is constructed and this argument acquires more and more "strength" each time that the area of one of the external triangle is found.

Furthermore, the abductive step of argument 2 has been transformed along the argumentation into a deductive step. We do not know when Ayla becomes aware that the chosen strategy is the good one. It is only at the end of the argumentation that Ayla explicitly makes it a solution of the problem. Ayla finally knows that the chosen strategy is correct because she is able to determine all the areas necessary to apply the rule (the area of the internal triangle can be determined subtracting each external area from the area of the rectangle).

12. It is ... it is 9.72 minus 18 minus 18 minus 9 is the area I was looking for.

I can prove it now, right?

13. I: Sure
The last argument derives from the previous arguments. It is deductive.

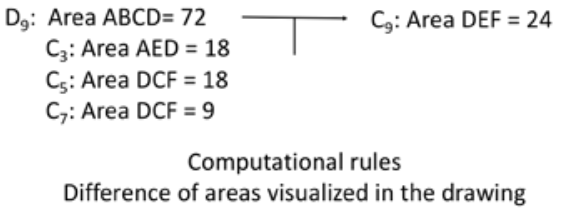

Argument 9 and Argument 2 are very similar and the warrant too. The strategic rule in Argument 2 and the definitory rule in Argument 9 are coincident at the end of the argumentation. 
Ayla constructs the proof directly following the argumentation.

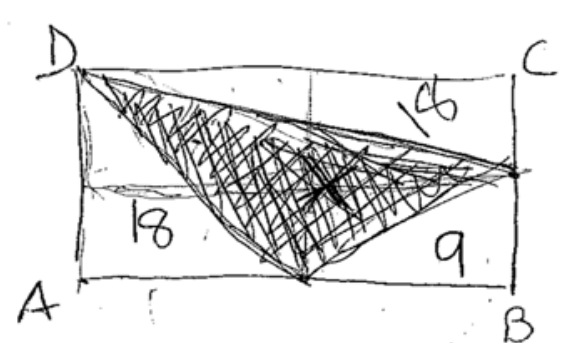

$$
\begin{gathered}
72-\left(\frac{1}{4}+\frac{1}{8}+\frac{1}{4}\right) 72=x \\
72-(18+9+18)=x \\
72-45=x \\
27=x
\end{gathered}
$$

Figure 6. Ayla's proof for Problem 1

The construction of the proof was not difficult for Ayla. There is cognitive unity between argumentation and proof. From the structural point of view, Argument 2, the only abductive argument, was transformed into a deductive one in the end. The proof is deductive as far as the steps inside the argumentation. In the proof, abduction based on strategic rule doesn't appear because this abduction was transformed into a deductive step at the end of the argumentation.

The structural distance between abduction based on strategic rule and deductive proof, is not a difficulty for students because at the end of the argumentation there is structural continuity between Argument 2 and the proof. Argument 9 is actually the step that guarantees the continuity between Argument 2 and the proof.

\section{Case 2}

The analyzed argumentation and proof is provided by Trevor (T), an American student.

In this argumentation, abduction based on strategic rule and abduction based on definitory rule are present.

For Trevor, the construction of the proof is not easy and he needs to write it twice to obtain a deductive proof.

At the beginning of the solution process, Trevor thinks that the areas of the two triangles ABO and ADO are equal because he considers the limit case: when $\mathrm{O}$ is coincident with $\mathrm{C}$.

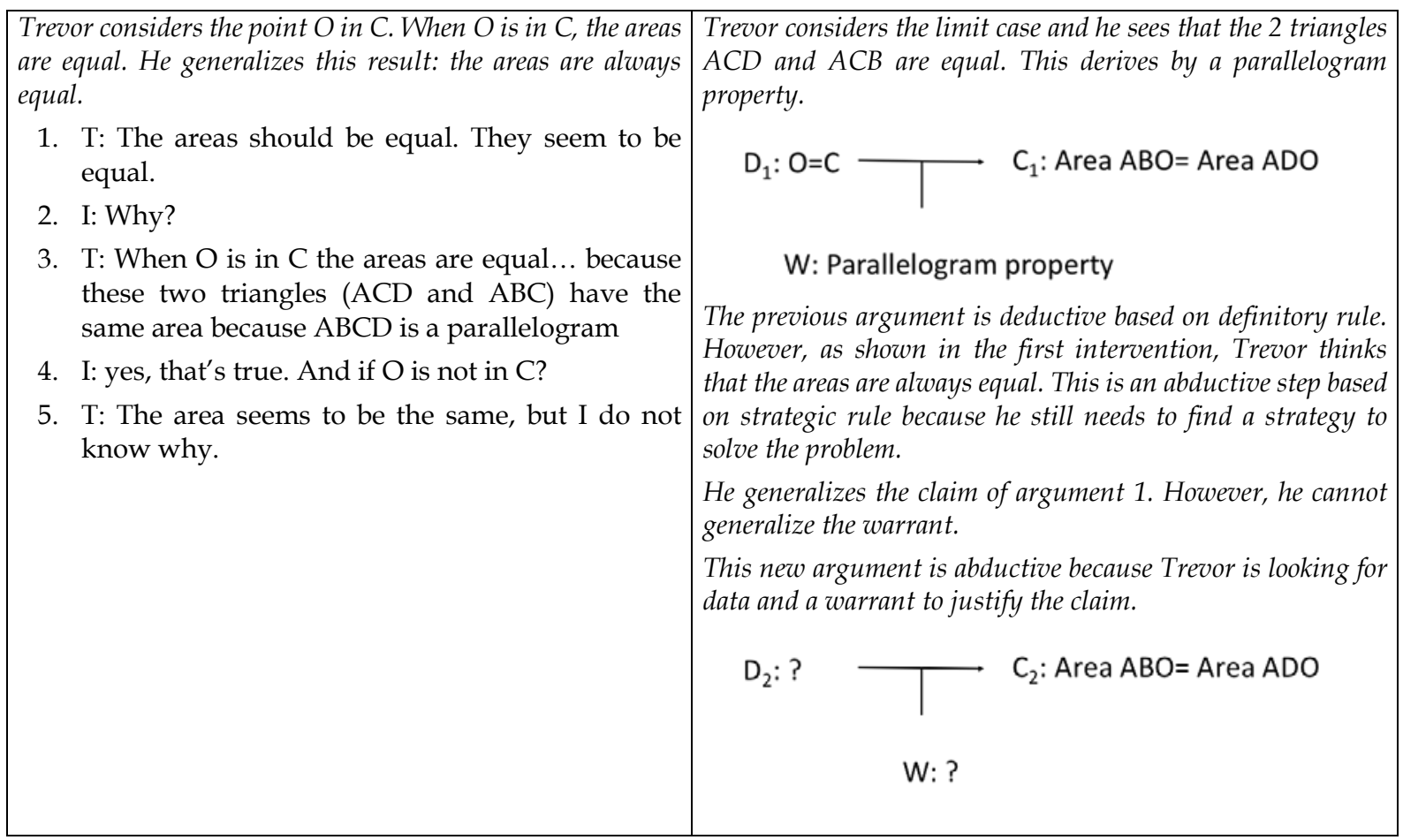

Trevor is looking for data and warrant to find a strategy to solve the problem. Argument 2 is not strong enough because it is based on a generalization on the limit case: because the two triangles have the same area when $\mathrm{O}$ coincides with $\mathrm{C}$, then the two triangles could have the same area also in the generic case. As in the previous case, argument 2 can be an undercoded abduction or a creative abduction. At this point, we do not know what Trevor has in mind. 
Trevor needs to find a strategy to state that the areas are equal. Trevor uses the area formula to justify the claim.

He thinks about the formula of the area to justify his hypothesis.

In this case he needs to find equal bases and equal heights for the two triangles $A O D$ and $A O B$

6. I: Why do you think they are equal?

$\mathrm{D}_{3}: ?$

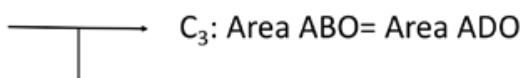

\section{W: Area Formula}

7. T: ...because...wait...if we calculate the area we Argument 3 is an overcoded abduction (the theorem is need to know the base and the height of the selected). Trevor looks for equal bases and heights inside the triangles. The area is base times height divided by triangles $A B O$ and $A D O$.

2. AO could be the base. To show that the two Observing the drawing, he states that the two triangles AOD triangles have the same area I need to show that and AOB have AO in common. He considers AO as their they have the same height. Because they have the base. However, he still needs to verify that the heights are same base AO, I need to show that they have the equal.

same heights. But they have equal heights, right?

8. I: Why do you think the heights are equal?

Trevor draws the heights in the figure

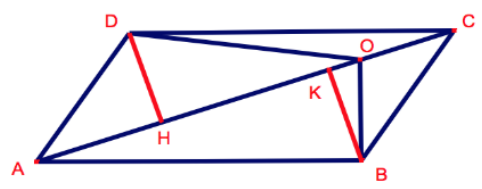

The argument 3 seems to be based on a definitory rule: the area for the two triangles $A O B$ and $A O D$.

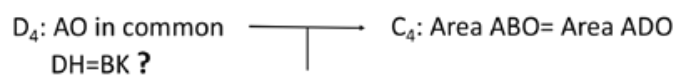

W: Area Formula

Argument 4 is very similar to argument 2 . This is why we can also consider it an abductive step based on the strategic rule: the area formula can be used to determine that the two areas are equal. For this reason, argument 4 can be considered an evolution of argument 2 . In argument 2, the warrant is still not identified. In argument 4 , the warrant is the area formula. This formula is both a strategic and a definitory rule.

Trevor needs to prove that the heights are equal to state that the areas are equal.

Trevor needs to prove that the heights are equal. He reconsiders the two triangles ABC and ADC. Because the two triangles have the same area and the same base $\mathrm{AC}$, their heights are equal.

Trevor needs to show that the areas are equal. He thinks back Trevor reconsiders the two triangles ABC and ADC. Because to the area formula as a warrant of the argument. He needs to they have equal area and the same base AC, their heights must find equal bases and equal heights for the two triangles $A O D$ be equal. and $A O B$

9. T: I can see them... they are equal, but I need to prove it. If $\mathrm{O}$ is in $\mathrm{C}$ we can consider $\mathrm{AO}$ the base, and the heights are equal because the area are equal. The heights do not change if we move $\mathrm{O}$ along AC, they are the same. Then the areas are equal.

10. I: Which areas?

11. The areas of the two triangles AOB and AOD. The base is $\mathrm{AO}$ and the two heights are $\mathrm{DH}$ and $\mathrm{KB}$, that are equal because in the two big triangles ACD and ACB they have to be equal.

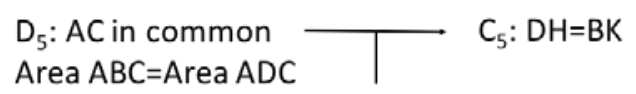

$$
W: \frac{A C \times D H}{2}=\frac{A C \times B K}{2}
$$

Argument 4 is now completed: the abductive step based on definitory rule can be transformed into a deductive step:

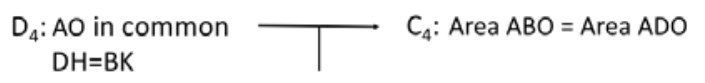

\section{W: Area Formula}

Argument 2, that was an abduction based on strategic rule, is now a deductive step. The strategy used by Trevor to solve the problem has been validated.

Trevor can finally construct the poof. 
Trevor knows he needs to construct a deductive proof but the first attempt of proof is still abductive as shown below.

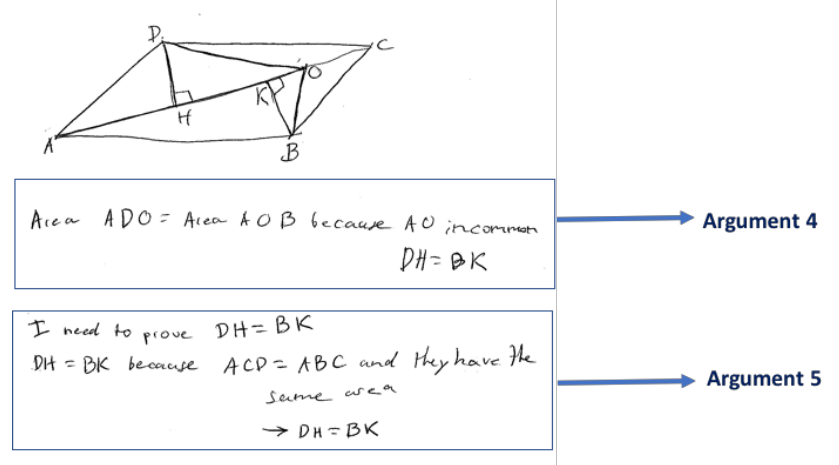

Figure 8. First attempt of Trevor's proof

We can observe that the first step in the proof corresponds to argument 4 and the second one corresponds to argument 5. The proof is still abductive: it is obtained as a backward process. The statement of argument 4 (Area $\mathrm{ADO}=\mathrm{Area} \mathrm{AOB})$ is assumed to be true. The reason justifying the claim is written after the statement was written.

The second part of the proof corresponds to argument 5. This part was written by Trevor because the interviewer asked him to justify the statement " $\mathrm{DH}$ is equal to $\mathrm{BK}^{\prime}$. Trevor writes the second part following the abductive step of argumentation. The statement is assumed to be true ( $\mathrm{DH}=\mathrm{BK})$ and the justification is given immediately after, following a forward process again. Furthermore, argument 5 should precede argument 4 in a deductive proof, but Trevor writes it after argument 4 , following the argumentation process.

The interviewer asked Trevor if the proof produced for problem 2 was deductive and he realized it was not. The interviewer asked him: "Could you try to write the proof in a deductive way?". Trevor wrote the proof as shown in the figure below:

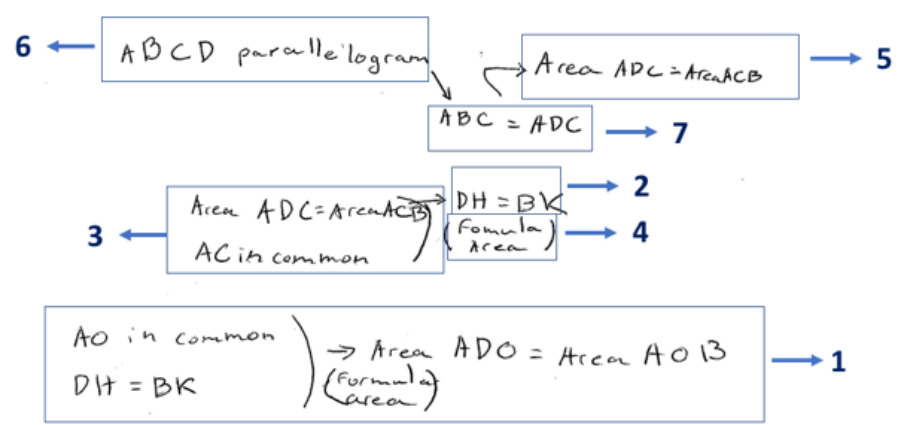

Figure 9. Trevor's proof representing the order statements were written

The proof is deductive but the student writes the proof starting from the last step and coming back to the first argument.

The numbers in the figure represent the order in which the statements were written. As shown by previous research (Pedemonte, 2007), the construction of proof was not easy for the student because the argumentation was mainly abductive in this case. Abduction based on strategic rule was present in the argumentation as far as abductions based on definitory rules. There is structural continuity between argumentation and proof. Trevor constructs the proof following the abductive steps of the argumentation: conclusion is written before data and a warrant. The structure in the proof follows abduction structure based on definitory rules.

\section{DISCUSSION}

The experiment presented in this paper, designed to analyze the relationship between abductive argumentation and deductive proof in Geometry, shows that in argumentation two kinds of abductions can be produced: abduction based on definitory rule and abduction based on strategic rule. The paper highlights that these two abductions are cognitively different. Previous research about the relationship between argumentation and proof in Geometry (Pedemonte, 2007), showed that abductive argumentation (based on definitory rules) can be an obstacle 
to the construction of a deductive proof. Sometimes, students are not able to construct a deductive proof because they spontaneously follow the abductive steps used in the argumentation. Based on work of Pierce and Eco, three types of abductions involved in proving processes were analyzed (overcoded, undercoded and creative abductions) to reveal the complexity of this analysis (Pedemonte \& Reid, 2011). Some types of abductions may present obstacle, both in the argumentation when the abduction occurs and later when the proof is constructed. However, the analysis of these types of abductions was performed considering abduction based on definitory rule. This paper highlights that there is another kind of abduction that is used by student to solve a geometrical problem: the abduction based on strategic rule.

This abduction can be distinguished by abduction based on definitory rule because it is not part of a single argument but it is present all along the argumentation process. This abduction is present at meta-level in the argumentation. Furthermore, as shown in Case 2, this abduction changes during the argumentation process:

- It can become a deductive step at the end of the argumentation if the strategy used by the students allows them to solve the problem (Argument 2 in Case 1; Argument 2 and Argument 4 in Case 2)

- It can be abandoned and never completed if the strategy cannot be used to solve the problem (Argument 1 in Case 1)

- It can stay an abduction if the student is not able to continue the process to solve the problem

In each case, this abduction can be situated at a different level in respect to the abduction based on definitory rule.

The paper also shows that the abduction as strategic rule doesn't affect the construction of a deductive proof because if the strategy is correct, this abduction can evolve into deduction at the end of the argumentation (as shown in Case 1).

Thus, the structural distance between argumentation and proof is maintained under control by students, because, as shown in Case 1, the only abductive step in the argumentation was transformed into a deductive one. This kind of abduction does not seem to prevent the construction of a deductive proof. Most students were able to construct a deductive proof for Problem 1 if they were able to find the gain strategy.

\section{CONCLUSIONS}

Previous research (Pedemonte 2007) showed that there is structural distance between abductive argumentation and deductive proof. This distance is a difficulty for the construction of the proof because students are not able to transform the abductive steps of argumentation into deductive steps in the proof.

This paper reveals that there are two types of abductions that can be considered in the argumentation: abduction based on strategic rules vs abduction based on definitory rules.

Proving process can be considered like a playing a game. To play a game it is important to know rules that are admissible in it (definitory rules) and rules that define the gain strategy. These rules are often implicit but are not less important. Definitory rules define the warrant in each argument, they represent the theorems and property that can be used to justify a specific claim. Strategic rules can also be inserted in the warrant but they justify the strategy chosen by students to solve the problem. Abduction based on strategic rules is generally formulated at the beginning of the resolution process and it is used all along the argumentation process. Instead, abduction based on definitory rules characterizes single steps of argumentation.

From the structural point of view, if the chosen strategic rules allow to solve the problem, abduction based on strategic rules can be transformed into a deduction at the end of the argumentation. Thus, this kind of abduction does not prevent the construction of a deductive proof. Structural distance between abductive argumentation based on strategic rule and deductive proof does not represent a difficulty to the construction of the proof.

From the educational point of view two considerations can be expressed. First of all, it is important to teach students definitory rules and especially strategic rules. These rules are often forgotten and the emphasis is given to the learning of definitory rules (Paavola, 2004). As Hintikka (1999) states, students are not taught how to reason well but to maintain their logical virtue (i.e., to avoid logical fallacies and to learn what is and what is not admissible and valid). It is important to teach them how to select a gain strategy to solve a problem as well to explicit which theorems or properties they can use. This is also confirmed by our study. Abduction based on strategic rules does not represent a cognitive difficulty for the construction of deductive proof.

A second important educational aspect derived by this study is to be aware about the importance of letting the students write more "proofs" before they get the deductive one. The interviewer can help students to overcome the structural distance between abductive argumentation based on definitory rule and deductive proof. In Case 2, the interviewer was able to help Trevor to construct the proof even if he struggled a lot before doing that. The interviewer suggested to Trevor to write the proof in a deductive form without ever interrupting Trevor's 
reasoning. He allowed him to write the proof twice. Trevor was not scared to make mistakes: he tried and then he refined the proof previously constructed until he had the definitive one.

\section{REFERENCES}

Antonini, S., \& Mariotti, M. A. (2003). Abduction and the explanation of anomalies: the case of proof by contradiction In Durand-Guerrier, V., Soury-Lavergne, S., \& Arzarello, F. (Ed.), Proceedings of the Sixth Conference of the European Society in Mathematics Education, Lyon, France.

Arsac G., Germain, G., \& Mante, M. (1991). Problème ouvert et situation-problème. Irem Lyon.

Arzarello, F., Micheletti, C., Olivero, F., \& Robutti, O. (1998a). A model for analysing the transition to formal proofs in geometry. In A. Olivier \& K. Newstead (Eds.) Proceedings of the Twentieth-second Annual Conference of the International Group for the Psychology of Mathematics Education, (Vol. 2, pp. 24-31) Stellenbosch, South Africa.

Arzarello, F., Micheletti, C., Olivero, F., \& Robutti, O. (1998b). Dragging in Cabri and modalities of transition from conjectures to proofs in geometry. In A. Olivier \& K. Newstead (Eds.) Proceedings of the Twentieth-second Annual Conference of the International Group for the Psychology of Mathematics Education, (Vol. 2 pp. 32-39) Stellenbosch, South Africa.

Balacheff, N. (1988). Aspects of proof in pupils' practice of school mathematics. In D. Pimm (Ed.), Mathematics, teachers and children (pp. 216 - 235). London: Hodder \& Stoughton.

Boero, P., Garuti, R., \& Mariotti M. A. (1996). Some dynamic mental processes underlying producing and proving conjectures. In L. Puig\& A. Gutierrez (Eds.), Proceedings of the Twentieth Conference of the International Group for the Psychology of Mathematics Education, (Vol. 2, pp. 121-128), Valencia.

Bonfantini, M., \& Proni, G. (1983). To guess or not to guess. In U. Eco \& T. Sebeok (Eds.), The sign of three: Dupin, Holmes, Peirce, (pp. 119-134). Bloomington, IN: Indiana University Press.

Cifarelli, V., \& Sáenz-Ludlow, A. (1996). Abductive processes and mathematics learning. In E. Jakubowski, D. Watkins, \& H. Biske (Eds.) Proceedings of the Eighteenth Annual Meeting of the North American Chapter of the International Group for the Psychology of Mathematics Education (Vol. I, pp. 161-166). Columbus, OH: ERIC Clearinghouse for Science, Mathematics, and Environmental Education.

Eco, U. (1983). Horns, Hooves, Insteps: Some Hypotheses on three types of abduction. In U. Eco \& T. Sebeok (Eds.). The sign of three: Dupin, Holmes, Peirce, (pp. 198-220). Bloomington, IN: Indiana University Press.

Eggs, E. (1994) Grammaire du discours argumentatif. Le topique, le générique, le figuré. Ed. Kimé, Paris.

Fann, K. T. (1970). Peirce's theory of abduction. The Hague, Holland: Martinus Nijhoff.

Fiallo, J., \& Gutierrez, A. (2017). Analysis of the cognitive unity or rupture between conjecture and proof when learning to prove on a grade 10 trigonometry course. Educational Studies in Mathematics, 96(2), 145-167. https:/ / doi.org/10.1007/s10649-017-9755-6

Garuti, R., Boero, P., Lemut, E., \& Mariotti, M. A. (1996). Challenging the traditional school approach to theorems: Proceedings of the International Group for the Psychology of Mathematics Education PME-XX, Valencia, vol. 2, 113-120.

Garuti, R., Boero, P., \& Lemut, E. (1998): Cognitive Unity of Theorems and Difficulty of Proof Proceedings of the International Group for the Psychology of Mathematics Education PME-XXII, Stellenbosch, vol. 2, 345-352.

Hintikka, J. (1998). The principle of mathematics revisited, Cambridge University Press.

Hintikka, J. (1998). What is abduction? The fundamental problem of contemporary epistemology, Transactions of the Charles S. Peirce Society, 34(3), 503-533.

Hintikka, J. (1999). 'What is Abduction? The fundamental Problem of Contemporary Epistemology', in Inquiry as Inquiry: A Logic of Scientific Discovery. Jaakko Hintikka Selected Papers, vol. 5, Dordrecht/Boston/London, Kluwer Academic Publishers, pp. 91-113. https:/ / doi.org/10.1007/978-94-015-9313-7_4

Hintikka, J., \& Bachman, J. (1991). What If? Toward Excellence in Reasoning. Mayfield, Mountain View, Calif. and London.

Inglis, M., Mejia-Ramos, J. P., \& Simpson, A. (2007). Modelling mathematical argumentation: The importance of qualification. Educational Studies in Mathematics, 66, 3-21. https:/ / doi.org/10.1007/s10649-006-9059-8

Knipping, C. (2003). Argumentation structures in classroom proving situations. In M. A. Mariotti (Ed.), Proceedings of the Third Conference of the European Society in Mathematics Education.

Knipping, C. (2008). A method for revealing structures of argumentation in classroom proving processes. ZDM, 40(3), 427-441. https:/ / doi.org/10.1007/s11858-008-0095-y 
Krummheuer, G. (1995). The ethnography of argumentation. In P. Cobb \& H. Bauersfeld (Eds.), The emergence of mathematical meaning: Interaction in classroom cultures, 229-269. Hillsdale, NJ: Lawrence Erlbaum Associates.

Krummheuer, G. (2007). Argumentation and participation in the primary mathematics classroom: Two episodes and related theoretical abductions. Journal of Mathematical Behavior, 26(1), 60-82. https://doi.org/10.1016/j.jmathb.2007.02.001

Lavy, I. (2006). A Case Study of Different Types of Arguments Emerging from Explorations in an Interactive Computerized Environment. The Journal of Mathematical Behavior, 25, 153-169. https:/ / doi.org/10.1016/j.jmathb.2006.02.006

Magnani, L. (2001). Abduction, reason and science: Processes of discovery and explanation. Dordrecht: Kluwer Academic Publishers. https:/ / doi.org/10.1007/978-1-4419-8562-0

Mason, J. (1996). Abduction at the heart of mathematical being. In E. Gray (Ed.) Thinking about mathematics \& Music of the spheres: Papers presented for the inaugural lecture of Professor David Tall. (pp. 34-40). Coventry: Mathematics Education Research Centre.

Nardi, E., Biza, I., \& Zachariades, T. (2012). “Warrant” revisited: Integrating mathematics teachers' pedagogical and epistemological considerations into Toulmin's model for argumentation. Educational Studies in Mathematics, 79, 157-173. https:/ / doi.org/10.1007/s10649-011-9345-y

Paavola, S. (2004). Abduction as a logic and methodology of discovery: The importance of strategies. Found. Sci., 9, 267-283. https://doi.org/10.1023/B:FODA.0000042843.48932.25

Park, W. (2017). Magnani's Manipulative abduction. In Magnani, Bertolotti (Eds.) Springer Handbook of Model-Based Science, Springer (pp. 197-213) https:/ / doi.org/10.1007/978-3-319-30526-4_9

Pedemonte, B. (2005). Quelques outils pour l'analyse cognitive du rapport entre argumentation et démonstration Recherche en didactique des mathématiques, 25(3), 313-348. http://rdm.penseesauvage.com/Quelques-outilspour-l-analyse.html

Pedemonte, B. (2007). How can the relationship between argumentation and proof be analysed? Educational Studies in Mathematics, 66, 23-41. https:/ / doi.org/10.1007/s10649-006-9057-x

Pedemonte, B. (2008). Argumentation and algebraic proof. ZDM - The International Journal on Mathematics Education, 40(3), 385-400. https:// doi.org/10.1007/s11858-008-0085-0

Pedemonte, B., \& Balacheff, N. (2016). Establishing links between conceptions, argumentation and proof through the ck\$-enriched Toulmin model. The Journal of Mathematical Behavior, 41, 104-122. https://doi.org/10.1016/j.jmathb.2015.10.008

Pedemonte, B., \& Reid, D. (2011). The role of abduction in proving processes, Educ. Stud. Math. 76, 281-303. https:/ / doi.org/10.1007/s10649-010-9275-0

Peirce, C. S. (1867). On the natural classification of arguments. Presented 9 April 1867 to the American Academy of Arts and Sciences. Proceedings of the American Academy of Arts and Sciences 7, 261-287. (Compiled in Peirce, C. S., 1960, 2.461-516).

Peirce, C. S. (1960). Collected papers Cambridge, MA: Harvard University Press.

Peirce, C. S. (1998). The Essential Peirce. Selected Philosophical Writings, vol. 21893-1913, the Peirce Edition Project, ed., Indiana University Press, Bloomington and Indianapolis.

Rivera, F. (2017). Abduction and the Emergence of Necessary Mathematical Knowledge, In Magnani, Bertolotti (Eds.) Springer Handbook of Model-Based Science, Springer (pp. 551-567)

Rivera, F. D., \& Becker, J. R. (2007). Abduction-induction (generalization) processes of elementary majors on figural patterns in algebra. The Journal of Mathematical Behavior, 26(2), 140-155. https://doi.org/10.1016/j.jmathb.2007.05.001

Toulmin, S. E. (2003). The uses of argument (updated edition of the 1958 book). Cambridge, UK: Cambridge University Press.

Weber, K., \& Alcock, L. (2005). Using warranted implications to understand and validate proof. For the Learning of Mathematics, 25(1), 34-38.

Wood, T. (1999). Creating a context for argument in mathematics class. Journal for Research in Mathematics Education, 30(2), 171-191. https:/ / doi.org/10.2307/749609 
Yackel, E. (2001). Explanation, Justification and argumentation in mathematics classrooms, Proceedings of the 25th Conference of the International Group for the Psychology of Mathematics Education PME-25, Van den HeuvelPanhuizen M. (ed.), vol. 4, 33-40, Utrecht.

Yackel, E., \& Rasmussen, C. (2002). Beliefs and norms in the mathematics classroom. In G. Leder, E. Pehkonen, \& G. Toerner (Eds.), Beliefs: A hidden variable in mathematics education? 313-330. Dordrecht, The Netherlands: Kluwer.

http://www.ejmste.com 